\title{
Regulation of Adult Neurogenesis by Excitatory Input and NMDA Receptor Activation in the Dentate Gyrus
}

\author{
Heather A. Cameron, Bruce S. McEwen, and Elizabeth Gould \\ Laboratory of Neuroendocrinology, The Rockefeller University, New York, New York 10021
}

\begin{abstract}
The effects of afferent input and $\mathrm{N}$-methyl-D-aspartate (NMDA) receptor activation on neurogenesis were examined in an intact system, the rat dentate gyrus, where neurons are naturally born in the adult. In the adult dentate gyrus, activation of NMDA receptors rapidly decreased the number of cells synthesizing DNA, whereas blockade of NMDA receptors rapidly increased the number of cells in the $\mathrm{S}$ phase identified with ${ }^{3} \mathrm{H}$-thymidine. Acute treatment with NMDA receptor antagonists increased the birth of neurons and increased the overall density of neurons in the granule cell layer. Lesion of the entorhinal cortex, the main excitatory afferent population to the granule neurons, also increased the birth of cells in the dentate gyrus. These results suggest that adult neurogenesis in the dentate gyrus of the rat is altered by afferent input, via NMDA receptors, and may be regulated naturally by endogenous excitatory amino acids.
\end{abstract}

[Key words: hippocampus, entorhinal cortex, granule cell, neurogenesis, cell division, glutamate, NMDA receptors]

Once development is complete, the vast majority of neuronal precursors in the mammalian brain undergo terminal differentiation and become unable to divide. In contrast, granule neurons of the rat dentate gyrus continue to be produced from immature precursors into adulthood. Cells that are born in the adult dentate gyrus migrate to the granule cell layer (Cameron et al., 1993), receive synaptic input (Kaplan and Hinds, 1977), extend axons into the mossy fiber layer (Stanficld and Trice, 1988), express a neuronal marker (Cameron et al., 1993), and survive for at least 1 month (Cameron et al., 1993). The unusually extended period of neurogenesis makes the dentate gyrus an interesting and useful system in which to study the factors that mediate neurogenesis.

A recent study has shown that axonal contact stimulates progression through the cell cycle in Drosophila neuronal precursors (Selleck et al., 1992), suggesting that afferent input may regulate neurogenesis. Studies performed in several in vitro systems have indicated that excitation regulates important cellular processes, including neuronal birth (Stillwell et al., 1973; Cone and Cone, 1976) and survival (Brenneman and Eiden, 1986;

\footnotetext{
Received Sept. 23, 1994; revised Dec. 5, 1994; accepted Dec. 9, 1994.

We thank Fernando Nottebohm and Mary E. Hatten for helpful comments on the manuscript. This work was supported by MH 52423, a grant from the American Paralysis Association, and a NARSAD Young Investigator Award (E.G.). H.A.C. was supported by NRSA Training Grant GM07524.

Correspondence should be addressed to Heather A. Cameron, The Rockefeller University, 1230 York Avenue, New York, NY 10021.

Copyright (C) 1995 Society for Neuroscience $0270-6474 / 95 / 154687-06 \$ 05.00 / 0$
}

Lipton, 1986). The NMDA subtype of glutamate receptors, in particular, has been shown to play an important role in developmental processes; blockade of these receptors inhibits migration (Komuro and Rakic, 1993) and survival (Balazs et al., 1988, 1990) of developing cerebellar granule neurons in vitro and increases cell birth and cell death in the developing subependymal layer and dentate gyrus (Gould et al., 1994). Although granule neurons in the dentate gyrus receive their major excitatory input from the entorhinal cortex via NMDA receptors (Collingridge, 1989), no previous studies have explored the possibility that excitatory input and NMDA receptor activation control neuronal birth in the adult. In order to test this hypothesis, we examined the numbcrs of newly born neurons using 'II-thymidine autoradiography and immunohistochemistry for the neuronal marker neuron-specific enolase (NSE) following treatment with drugs which either activate or block NMDA receptors or lesion of the entorhinal cortex.

\section{Materials and Methods}

Animal treatments. Adult ( $>3$ months old) male Sprague--Dawley rats were used in all experiments ( $n=5$ for each group). In the first experiment, animals were injected with NMDA $(30 \mathrm{mg} / \mathrm{kg}$, i.p.) in saline or saline alone. They were given an injection of ${ }^{3} \mathrm{H}$-thymidine $(5.0 \mathrm{mCi}$ ${ }^{3} \mathrm{H}$-thymidine/kg, i.p.; New England Nuclear, specific activity $80 \mathrm{Ci} /$ mmol; this dose was used in all four experiments) $1 \mathrm{hr}$ after treatment and were perfused $1 \mathrm{hr}$ after ${ }^{3} \mathrm{H}$-thymidine injection. This survival time allows for the incorporation of ${ }^{3} \mathrm{H}$-thymidine by cells synthesizing DNA, but not for the completion of mitosis (Lewis, 1978; Nowakowski et al., 1989) or migration (Cameron et al., 1993). In the second experiment, animals were injected with MK-801 $(1.0 \mathrm{mg} / \mathrm{kg}$ in saline, i.p.; gift of Merck, Sharpe and Dohme), a specific noncompetitive NMDA antagonist (Vezzani et al., 1989), CGP 37849 in saline $(5.0 \mathrm{mg} / \mathrm{kg}$ in saline, i.p.; gift of Ciba Geigy), a specific competitive NMDA receptor antagonist (Schmutz et al., 1990), or saline alone. These doses are sufficient to block NMDA receptors (Vezzani et al., 1989; Schmutz et al., 1990). The rats were injected with ${ }^{3} \mathrm{H}$-thymidine $1 \mathrm{hr}$ after treatment and were perfused $1 \mathrm{hr}$ after ${ }^{3} \mathrm{H}$-thymidine injection. In the third experiment, animals were injected with the same doses of MK-801, CGP 37849 , and saline as in the second experiment and were injected with ${ }^{3} \mathrm{H}$-thymidine $1 \mathrm{hr}$ later, but they were perfused following a 4 week survival interval.

In the fourth expcriment, animals wcre anesthetized with Nembutal and Metofane, and unilateral stereotaxic lesions of the medial entorhinal cortex were made with $0.5 \mu \mathrm{l}$ of a $1 \%$ w:v solution of ibotenic acid in saline using stereotaxic coordinates AP -5.2 , LM 6.2, DV 6.1 (from Paxinos and Watson, 1982). Ibotenic acid is an excitotoxin that kills cells whose somata are located at the site of the lesion while sparing fibers of passage, and has been used extensively to produce discrete lesions in the forebrain (Zimmer et al., 1989). Two days after the lesion, when synaptic degeneration in the dentate gyrus is maximal (Matthews et al., 1976a; Cotman and Nadler, 1978), the rats were injected with ${ }^{3} \mathrm{H}$-thymidine and perfused $1 \mathrm{hr}$ later. Since virtually all connections from the entorhinal cortex to the granule neurons are ipsilateral (Steward, 1976), comparisons between lesion and control were made within brains. 
Histological procedures. Following treatments, rats were anesthetized with Metofane and transcardially perfused with $4 \%$ paraformaldehyde. The brains were postfixed overnight in $4 \%$ paraformaldehyde and cut in the coronal plane with a Vibratome $(40 \mu \mathrm{m})$ into a bath of phosphatebuffered saline (PBS). For the first, second, and fourth experiments, ${ }^{3} \mathrm{H}-$ thymidine autoradiography followed by Nissl staining with cresyl violet was performed on brain sections from all animals according to a previously published protocol (Gould et al., 1994). Briefly, the sections were mounted onto gelatinized slides, dried, rinsed in distilled water, dried, dipped in photographic emulsion (NTB-2, Kodak), and stored in the dark at $4^{\circ} \mathrm{C}$ for 4 weeks. The slides were then developed in Dektol (Kodak), rinsed in distilled water, fixed in Ektaflo (Kodak), rinsed again, stained for Nissl using cresyl violet, and coverslipped under Permount.

For the third experiment, combined NSE immunohistochemistry, ${ }^{3} \mathrm{H}$ thymidine autoradiography, and Nissl staining were performed on brain sections as previously described (Cameron et al., 1993). The sections were rinsed in PBS and incubated for $24 \mathrm{hr}$ in a solution containing polyclonal antisera to NSE (Polysciences, diluted 1:2000 in PBS). Previous studies have shown that in the brain (Schmechel et al., 1980; Marangos and Schmechel, 1987), and specifically in the adult dentate gyrus (Cameron et al., 1993), NSE is expressed exclusively by neurons. The sections were rinsed in PBS and incubated for $2 \mathrm{hr}$ in a solution of biotinylated anti-rabbit secondary antibodies in PBS. Following this, the sections were rinsed again and incubated for $2 \mathrm{hr}$ in a solution of avidin-biotin-HRP in PBS. The sections were rinsed again and reacted with diaminobenzidine and hydrogen peroxide in PBS for $15 \mathrm{~min}$. The sections were rinsed again, mounted onto gelatinized slides, dried, rinsed in distilled water, dried, dipped in photographic emulsion (NTB2, Kodak), and stored in the dark at $4^{\circ} \mathrm{C}$ for 4 weeks. The slides were then developed in Dektol (Kodak), rinsed in distilled water, fixed in Ektaflo (Kodak), rinsed again, stained for Nissl using cresyl violet, and coverslipped under Permount. Control sections were processed as described above with omission of the primary antisera and revealed no nonspecific staining of secondary antibodies.

Data analysis. Data analysis involved counting the number of ${ }^{3} \mathrm{H}-$ thymidine-labeled cells (cells with $\geq 5$ silver grains over the nucleus; this value is $>20$ times the background level) in the granule cell layer and hilus on ncuroanatomically matched sections from the middle dentate gyrus. In the fourth experiment, labeled cells were counted at three different levels of the dentate gyrus: rostral $(\approx \mathrm{AP}-2.6)$, middle $(\approx \mathrm{AP}$ -4.2 ), and temporal $(\approx \mathrm{AP}-5.8$ ) according to Paxinos and Watson (1982). For the third experiment, a distinction was made between NSEimmunoreactive and NSE-nonimmunoreactive ${ }^{3} \mathrm{H}$-thymidine-labeled cells. In addition, the density of granule neurons in the granule cell layer was determined in the third experiment by counting (at $400 \times$ ) the number of NSE-immunoreactive granule cells within an oval of known area placed under the camera lucida drawing tube positioned in the center of the suprapyramidal blade. The cross-sectional area of each region was determined with a Zeiss Interactive Digitizing Analysis System and the data were expressed as number of cells per $10^{6} \mu \mathrm{m}^{2}$. No ${ }^{3} \mathrm{H}$-thymidine-labeled cells were observed in other neuronal regions, nor were any NSE-immunorcactive cells observed in any other area in the long survival experiment, indicating that ${ }^{3} \mathrm{H}$-thymidine labeling is evidence of DNA synthesis during cell division and not of random DNA repair.

\section{Results}

\section{NMDA receptor activation}

In order to investigate the hypothesis that NMDA receptor activation alters the rate of cell birth in the adult, we determined the number of dividing cells in the dentate gyrus of adult $>3$ months old) rats treated with a single injection of the NMDA receptor agonist NMDA. Following treatment, the rats received a single injection of ${ }^{3} \mathrm{H}$-thymidine and were perfused $1 \mathrm{hr}$ later. Following treatment with NMDA, the density of ${ }^{3} \mathrm{H}$-thymidinelabeled cells in the dentate gyrus was significantly decreased compared to saline-injected controls (Fig. 1A). This treatment produced a large (>sixfold) decrease in cell birth, but did not completely terminate DNA synthesis in this population. In both groups the ${ }^{3} \mathrm{H}$-thymidine-labeled cells were located primarily in the region close to the border of the hilus and the granule cell layer and were distributed such that approximately $60 \%$ were
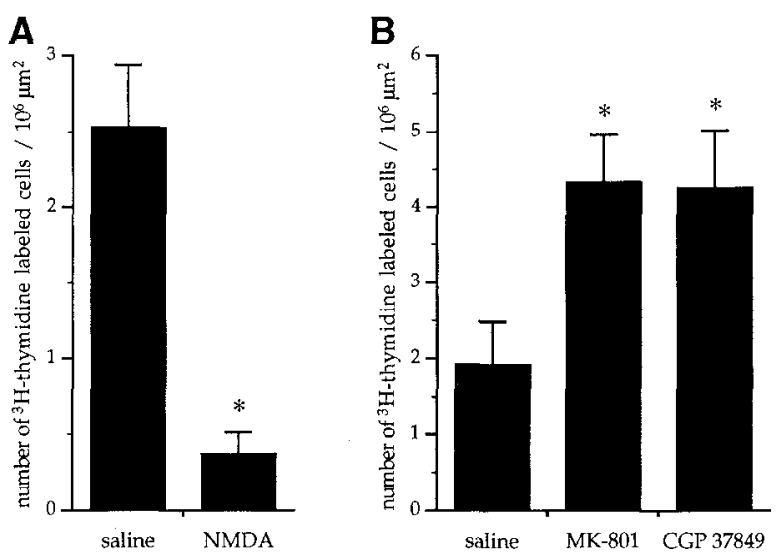

Figure I. The effects of treatment with NMDA receptor agonist and antagonists on the number of cells synthesizing DNA in the adult rat dentate gyrus. $A$, Inhibition of cell birth in the adult dentate gyrus following a single treatment with $N$-methyl-D-aspartate. NMDA-treated rats had significantly fewer ${ }^{3} \mathrm{H}$-thymidine-labeled cells in the dentate gyrus (granule cell layer and hilus combined) than controls $(p<0.05$; Student's $t$ test following $\log$ transformation in order to achieve homogeneity of variance; $n=5$ in each group). Bars represent mean + SEM; asterisk indicates significant difference from saline-injected control. $B$, Enhancement of cell birth in the adult dentate gyrus following a single treatment with the NMDA receptor antagonists MK-801 or CGP 37849 . Rats treated with MK-801 or CGP 37849 had significantly more ${ }^{3} \mathrm{H}$-thymidine-labeled cells in the dentate gyrus than controls $(p$ $<0.05$; ANOVA followed by Tukey HSD post hoc comparisons). Bars represent mean + SEM; asterisk indicates significant difference from control.

apposed to cells in the granule cell layer, while the remaining $40 \%$ were located in the hilus.

\section{NMDA receptor blockade, short survival period}

We next investigated the possibility that blockade of NMDA receptors increases the rate of cell birth in the adult dentate gyrus by treating rats with NMDA receptor antagonists. These rats received a single injection of either the specific competitive NMDA receptor antagonist CGP 37849 (Schmutz et al., 1990) or the specific noncompetitive NMDA receptor antagonist MK801 (Vezzani et al., 1989) followed by an injection of ${ }^{3} \mathrm{H}$-thymidine with a $1 \mathrm{hr}$ postinjection survival period. Following treatment with either CGP 37849 or MK-801, a significant increase in the density of ${ }^{3} \mathrm{H}$-thymidine-labeled cells was observed in the dentate gyrus (Fig. $1 B$ ). Most ${ }^{3} \mathrm{H}$-thymidinc-labcled cells in the NMDA receptor antagonist-treated brains were found in aggregations of 2-8 labeled cells located at the border of the granule cell layer and the hilus (Fig. 2A).

\section{NMDA receptor blockade, long survival period}

Due to the short post- ${ }^{3} \mathrm{H}$-thymidine injection survival intervals employed in the first and second experiments, it was not possible to positively identify ${ }^{3} \mathrm{H}$-thymidine-labeled cells as neurons or neuronal precursors using the neuronal marker NSE, as this protein is expressed by differentiated neurons 2-4 weeks after their final division (Cameron et al., 1993). In order to determine whether treatment with NMDA receptor antagonists increases the birth of neurons, the rats were treated with either MK-801 or CGP 37849 , injected with ${ }^{3} \mathrm{H}$-thymidine, and allowed to survive for 4 weeks. A single injection of CGP 37849 or MK-801 resulted in a significant increase in the density of ${ }^{3} \mathrm{H}$-thymidinelabeled NSE-immunoreactive cells in the granule cell layer of 

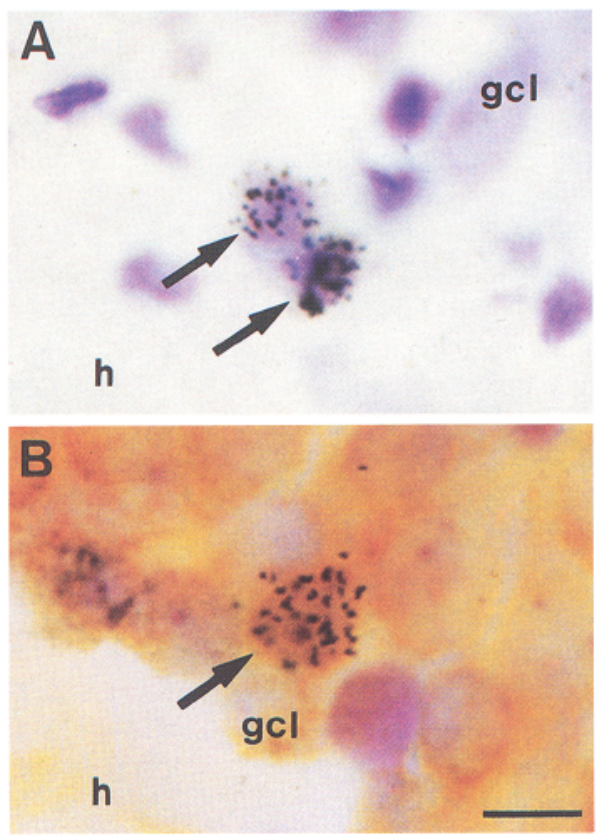

Figure 2. Photomicrographs of ${ }^{3} \mathrm{H}$-thymidine-labeled cells in the dentate gyrus. A, Dividing cells (arrows) labeled by ${ }^{3} \mathrm{H}$-thymidine autoradiography and Nissl staining, located in the hilus $(h)$ of the dentate gyrus near the border of the granule cell layer $(\mathrm{gcl}) . \mathrm{B}$, Neuron (arrow) born in the adult, labeled with ${ }^{3} \mathrm{H}$-thymidine and NSE immunohistochemistry, in the granule cell layer of the dentate gyrus. After 4 weeks, newly generated neurons are morphologically indistinguishable from surrounding cells in the granule cell layer. Scale bar in $B$ equals $20 \mu \mathrm{m}$ and applies to both $A$ and $B$.

the dentate gyrus (Fig. 3), suggesting that neurogenesis is stimulated by NMDA receptor blockade. Quantitative analysis of granule cell layer cross-sectional area showed no significant changes following treatment with MK-801 or CGP 37849, indicating that changes in cell density actually reflect changes in the number of cells. In treated animals, as in controls, these newly born neurons were located in the granule cell layer and were morphologically identical to the surrounding granule neurons (Fig. $2 B$ ). In contrast, the number of ${ }^{3} \mathrm{H}$-thymidine-labeled cells that were not immunoreactive for NSE did not increase following treatment with NMDA receptor antagonists (Fig. 3). A single treatment with CGP 37849 resulted, after 4 weeks, in a $24 \%$ increase in the density of neurons in the granule cell layer (Fig. 4), suggesting that the increased rate of neurogenesis results in a net increase in the number of granule neurons. The number of neurons in the granule cell layer following treatment with MK-801 was between that of the control group and the CGP 37849 group (Fig. 4).

\section{Removal of afferent input}

We next investigated the possibility that input from the entorhinal cortex, the chief excitatory afferent population to the granule neurons (Steward, 1976), which involves NMDA receptor activation (Collingridge, 1989), mediates the rate of cell birth. Unilateral lesion of the medial entorhinal cortex resulted in a significant increase in the number of ${ }^{3} \mathrm{H}$-thymidine-labeled cells in the dentate gyrus on the side of the lesion compared to the control side (Fig. 5A). The increase in ${ }^{3} \mathrm{H}$-thymidine-labeled cells was observed at both middle and temporal, but not rostral, levels of the dentate gyrus (Fig. 5A). Quantitative analysis of the cross-

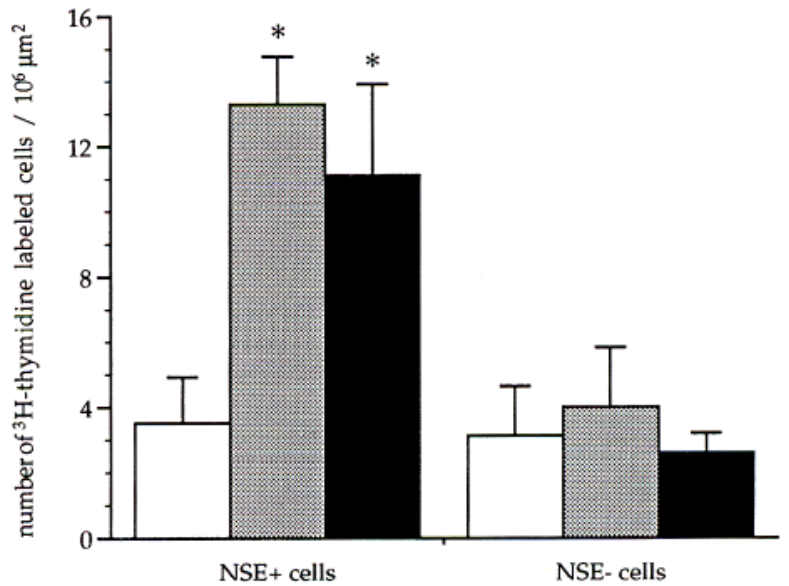

Figure 3. Stimulation of neurogenesis following a single treatment with the NMDA receptor antagonists MK-801 or CGP 37849. The density of NSE-immunoreactive (NSE+) ${ }^{3} \mathrm{H}$-thymidine-labeled neurons in the granule cell layer is increased compared to saline-injected values (open bars) following treatment with NMDA receptor antagonists MK801 (gray bars) or CGP 37849 (black bars) $(p<0.05$; ANOVA followed by Tukey HSD post hoc comparisons). NSE-nonimmunoreactive (NSE-) ${ }^{3} \mathrm{H}$-thymidine-labeled cell density in the granule cell layer was not altered by NMDA receptor antagonist treatment. White bars represent saline-injected control rats (mean + SEM), gray bars represent MK-801-treated rats, black bars represent CGP 37849-treated rats. Asterisk indicates significant difference from control.

sectional areas of the granule cell layer and hilus showed no significant changes following entorhinal cortex lesion. Examination of the entorhinal cortex revealed areas of high pyknotic cell density and low density of healthy cells in the medial entorhinal cortex at the site of the lesion (Fig. 5B).

\section{Discussion}

The results of this study show that activation of NMDA receptors results in a significant reduction in the rate of cell birth in

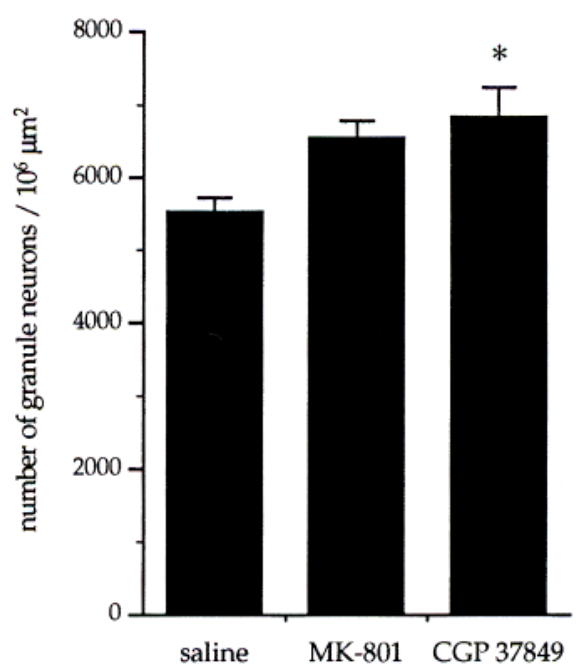

Figure 4. Increased density of neurons in the granule cell layer following treatment with NMDA receptor antagonists. Treatment with CGP 37849 resulted in significantly more NSE-immunoreactive cells, that is, granule neurons, in the granule cell layer compared to controls ( $p<0.05$; ANOVA followed by Tukey HSD post hoc comparisons). Bars represent mean + SEM; asterisk indicates significant difference from control. 

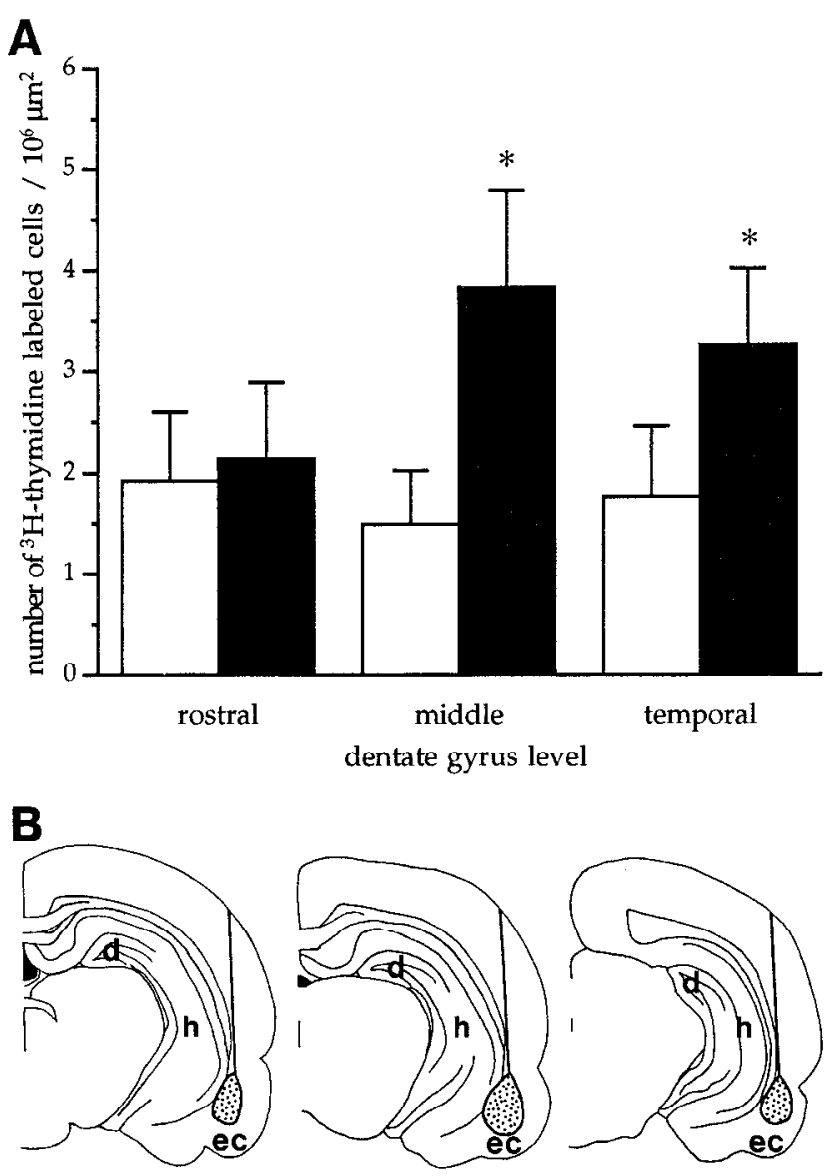

Figure 5. Stimulation of cell birth following removal of afferent input. $A$, Increased density of ${ }^{3} \mathrm{H}$-thymidine-labeled cells in the dentate gyrus granule cell layer following partial destruction of the entorhinal cortex. Lesion of medial entorhinal cortex resulted in significantly more ${ }^{3} \mathrm{H}$ thymidine cells on the side ipsilateral to the lesion (black bars) compared to the contralateral side (open bars) in middle and temporal regions of the dentate gyrus $1 \mathrm{hr}$ after ${ }^{3} \mathrm{H}$-thymidine injection $(p<0.05$; two-tailed paired Student's $t$ test). The rostral level corresponds to $\approx \mathrm{AP}$ -2.6 , middle corresponds to $\approx \mathrm{AP}-4.2$, and temporal corresponds to $\approx \mathrm{AP}-5.8$, according to Paxinos and Watson (1982). Asterisk indicates significant difference from control side. $B$. Schematic drawings showing rostral-caudal extent of the entorhinal cortex lesions. Black line indicates site of lesion; stippling indicates areas of degeneration characterized by high density of pyknotic cells and low density of healthy cells compared to the nonlesioned side. $d$, dentate gyrus; $h$, hilus; $e c$, entorhinal cortex.

the dentate gyrus, whereas deactivation of NMDA receptors, through removal of input or pharmacological blockade, results in a significant increase in the rate of cell birth. Many of these newly born cells become neurons that survive for at least 4 weeks and add to the total population of granule cells.

\section{Methodological considerations}

The finding that MK-801 produced a slightly greater increase in the number of ${ }^{3} \mathrm{H}$-thymidine-labeled cells compared to CGP 37849 in the short- and long-term studies while having a smaller effect than CGP 37849 on total cell density in the long-term study may be explained by the more rapid action and elimination of MK-801. MK-801 reaches its maximum brain concentration 10-30 min after intraperitoncal injection and is rapidly eliminated (Vezzani et al., 1989), whereas CGP 37849 is maximally effective 2 hr after intraperitoneal injection and is longer acting (Schmutz et al., 1990; Massieu et al., 1993).

The increase in granule cell density observed following NMDA receptor antagonist treatment appears relatively large compared to the increase observed in ${ }^{3} \mathrm{H}$-thymidine-labeled NSE-immunorcactive cells. However, it is likely that the observed increase in ${ }^{3} \mathrm{H}$-thymidine-labeled cells underestimated the actual changes in cell birth produced by NMDA receptor antagonist treatment for several reasons. First, the autoradiographic emulsion can detect ${ }^{3} \mathrm{H}$ only in the top $3 \mu \mathrm{m}$ of the $40 \mu \mathrm{m}$ section (Feinendegen, 1967), so the number of ${ }^{3} \mathrm{H}$-thymidinelabeled cells observed underestimates the number of ${ }^{3} \mathrm{H}$-thymidine-incorporaling cells in the section. For the total density counts, however, granule neurons throughout the entire thickness of the section were counted. Second, the maximal effect of NMDA blockade on cell birth may not have occurred during the time of ${ }^{3} \mathrm{H}$-thymidine availability. For example, CGP 37849 is maximally effective at blocking NMDA receptors $2 \mathrm{hr}$ after intraperitoneal injection (Schmutz et al., 1990; Massieu et al., 1993), the time at which the rats in the short survival study were perfused, so the observed effect of CGP 37849 on cell birth is likely to underestimate the actual increase in cell birth produced by this drug. Third, CGP 37849 is available in the brain for several hours (Schmutz et al., 1990; Massieu et al., 1993), while ${ }^{3} \mathrm{H}$-thymidine is available for only $1 \mathrm{hr}$. Fourth, effects on cell birth initiated by NMDA receptor blockade may persist beyond the time when the drug is present in the brain, resulting in increases in cell division through several cell cycles.

Following lesion of the entorhinal cortex, the increasc in ${ }^{3} \mathrm{H}$ thymidine-labeled cells was observed at both middle and temporal, but not rostral, levels of the dentate gyrus. The placement of these lesions within the entorhinal cortex may account for the regional differences in effects; the lesion was made in the medial entorhinal cortex, which projects primarily to middle and temporal levels of the dentate gyrus (Steward, 1976). In contrast, the rostral level of the dentate gyrus receives projections primarily from the lateral entorhinal cortex (Steward, 1976) which was spared in all lesioned animals of this study. Following entorhinal cortex lesion, the number of degenerating terminals in the dentate gyrus is maximal at $2 \mathrm{~d}$ following surgery (Matthews et al., 1976a), the survival time used in this study. At later time points after entorhinal cortex lesion, the number of excitatory synapses begins to rise, presumably due to collateral sprouting, and eventually reaches normal, unlesioned levels (Matthews et al., 1976b). Although our results indicate that cell birth is stim ulated when the number of excitatory synapses is low, it is presently unknown whether regenerative synapses, that is, those which form at postlesion survival times greater than $2 \mathrm{~d}$, are capable of inhibiting cell birth in this region. Future postlesion time course studies will seek to determine whether the number of excitatory synapses are negatively correlated with the rate of cell birth in this region.

\section{Mechanisms underlying inhibition of neurogenesis}

The results of our lesion study indicate that excitatory afferents from the entorhinal cortex normally inhibit cell birth in the dentate gyrus. This pathway may mediate neurogenesis in this system through two, not mutually exclusive, mechanisms. First, axonal contact may inhibit the birth of granule neurons. A previous study performed in the CNS of Drosophila has shown that axons selectively approach neuronal precursors and that contact with these axons stimulates neuroblasts to undergo their final division 
(Selleck et al., 1992). If this scenario occurs in the rat dentate gyrus, then removal of axons could induce proliferation, whereas innervation by perforant path axons could stimulate a final division. Second, excitation may inhibit neurogenesis in the dentate gyrus. In this regard, it is relevant that activation of glutamate receptors has been shown to decrease the birth of astroglia (Condorelli et al., 1989). Our results showing that NMDA inhibits cell birth and MK-801 or CGP 37849 stimulates cell birth strongly suggest that NMDA receptor-mediated excitation plays a role in regulating neuronal birth.

Although the results of this study indicate that NMDA receptor activation inhibits neurogenesis, there is currently no evidence to indicate that this inhibition occurs through synapses located on granule neuron precursors. NMDA receptors have very high agonist affinity (Blanton and Kriegstein, 1992) and are present early in development (Riva et al., 1994), making them ideally suited to receive nonsynaptic input and thus regulate developmental processes, such as neuronal birth, prior to synaptogenesis. Previous studies in other systems have shown that NMDA receptors can be activated prior to synapse formation (Blanton et al., 1990; Blanton and Kriegstein, 1992). During development, NMDA receptor channels can be activated by glutamate released by neighboring cells, even after action potential blockade, to producc a background current (Blanton and Kriegstein, 1992). These findings raise the possibility that NMDA receptor regulation of neuronal birth is not mediated synaptically. It is possible that glutamate released from neighboring astrocytes (Parpura et al., 1994) is responsible for the NMDA receptor-mediated inhibition of neurogenesis in the dentate gyrus. The observation that axonal growth cones release glutamate that can activate NMDA receptors in the absence of mature synapses (Young and Poo, 1983) presents another nonsynaptic method for NMDA receptor-mediated inhibition. However, the finding that lesion of the entorhinal cortex has an effect on neuronal birth that is virtually identical to NMDA receptor blockade suggests that the perforant pathway is at least indirectly involved in suppression of neurogenesis.

\section{Effects of excitatory input on cell survival}

Studies performed in several other systems have shown that excitatory input and/or NMDA receptors regulate cell death (Balazs et al., 1988, 1990). We have shown that NMDA receptor activation regulates cell birth and cell death in the developing dentate gyrus; blockade of NMDA receptors during the first postnatal week substantially increases the number of dividing and degenerating cells. The increase in cell death outweighs the increase in cell birth such that a decrease in the total number of granule neurons results (Gould et al., 1994). However, the present study showed no evidence of increased cell death in the dentate gyrus with NMDA receptor antagonist treatment in adulthood. Since only two time points after drug treatment $(2 \mathrm{hr}$ and 4 weeks) were examined in this study, it is possible that granule neurons die but that degenerating cells were indetectable at the time points examined. However, the observation that the number of granule neurons actually increases with CGP 37849 treatment indicates that the predominant action of NMDA receptor blockade on the adult granule neuron population is to increase cell birth.

The role of excitatory input in dentate gyrus development and maintenance

Several lines of evidence indicate that excitatory input naturally regulates the birth of cells in the rat dentate gyrus throughout lifc. First, the timing of development of excitatory input and granule cell genesis is consistent with this possibility. Excitatory synapses are immature (Cotman et al., 1973; Crain et al., 1973) and the density of NMDA receptors is still rising (Tremblay et al., 1988) when granule cell birth begins and peaks (Schlessinger et al., 1975). Perforant path axons enter the dentate gyrus (Loy et al., 1977), excitatory synapses are formed (Crain et al., 1973), and NMDA receptor densities reach a maximum (Tremblay et al., 1988) at the same time granule cell birth begins to diminish (Schlessinger et al., 1975). Second, we have shown that blockade of NMDA receptors on postnatal day 5, the time of maximal neurogenesis, further increases the birth of cells in the dentate gyrus (Gould et al., 1994), suggesting that NMDA receptor activation normally slows neuronal birth during the postnatal period. Third, the results from these experiments collectively suggest that neurogenesis in the adult dentate gyrus is normally suppressed by afferent input via NMDA receptor activation. However, inhibition of neurogenesis is not complete in the adult dentate gyrus under normal conditions, since neurons continue to be born at a slow rate (Kaplan and Hinds, 1977; Cameron et al., 1993). This slow rate of neuronal birth, which can be suppressed by NMDA receptor activation and enhanced by NMDA receptor inactivation, may provide a means whereby natural alterations in the degree of excitatory inpul control the number of new granule neurons.

\section{Possible consequences of alterations in granule cell number}

Many of the cells that are born in the dentate gyrus following treatment with NMDA receptor antagonists become neurons that reside in the granule cell layer, appear morphologically indistinguishable from the surrounding granule neurons, and express NSE, which is a reliable marker of functional neuronal metabolic activity (Rosenstein, 1993). These new granule cells survive for at least 4 weeks, and add to the total population of granule neurons. It is likely that the increased number of granule neurons which results from treatment with NMDA receptor antagonists has functional consequences for the dentate gyrus.

Because newly born granule neurons take 3-4 weeks to mature (Cameron et al., 1993), functional effects of increased granulc cell number are likely to be observed only over a relatively long time course. The dentate gyrus is believed to be involved in spatial memory (see Jarrard, 1993, for review). Studies comparing different strains of mice have suggested a link between the number of hippocampal neurons and the ability to learn spatial tasks (Wimer et al., 1978, 1980; Symons et al., 1988). In addition, NMDA receptor activation has been shown to play a role in spatial learning (Butelman, 1989; McLamb et al., 1990; Bischoff and Teidtke, 1992; Davis et al., 1992). The current findings present the possibility that treatment with NMDA receptor antagonists would also have delayed, yet long-lasting, effects on the learning ability of rats. NMDA receptor regulation of neurogenesis may provide a mechanism for stabilizing the granule neuron population during periods of active learning, while increasing storage capacity by adding new neurons during periods of inactivity.

\section{References}

Balazs R, Jorgensen OS, Hack N (1988) N-methyl-D-aspartate promotes the survival of cerebellar granule cells in culture. Neuroscience 27 : $437-451$.

Balazs R, Hack N, Jorgensen OS (1990) Interactive effects involving different classes of excitatory amino acid receptors and the survival of cerebellar granule cells in culture. Int J Dev Neurosci 8:347-360. 
Bischoff C, Teidtke PI (1992) Competitive and non-competitive NMDA receptor antagonists in spatial learning tasks. Eur J Pharmacol 213: 269-273.

Blanton MD, Kriegstein AR (1992) Properties of amino acid neurotransmitter receptors of embryonic cortical neurons when activated by exogenous and endogenous agonists. J Neurophysiol 67:11851200.

Blanton MD, Lo Turco JJ, Kriegstein AR (1990) Endogenous neurotransmitter activates $N$-methyl-D-aspartate receptors on differentiating neurons in embryonic cortex. Proc Natl Acad Sci USA 87:80278030.

Brenneman DE, Eiden LE (1986) Vasoactive intestinal peptide and electrical activity influence neuronal survival. Proc Natl Acad Sci USA 83:1159-1162.

Butelman ER (1989) A novel NMDA antagonist, MK-801, impairs performance in a hippocampal-dependent spatial learning task. Pharmacol Biochem Behav 34:13-16.

Cameron HA, Woolley CS, McFwen RS, Gould F. (1993) Differentiation of newly born neurons and glia in the dentate gyrus of the adult rat. Neuroscience 56:337-344.

Collingridge GL (1989) Synaptic function of $N$-methyl-D-aspartate receptors in the hippocampus. In: The hippocampus: new vistas, Vol 52 (Chan-Palay V, Kohler C, eds), pp 329-346. New York: Liss.

Condorelli DF, Ingrao F, Magri G, Brumo V, Nicoletli F, Avola R (1989) Activation of excitatory amino acid receptors reduces thymidine incorporation and cell proliferation rate in primary cultures of astrocytes. Glia 2:67-69.

Cone C, Cone C (1976) Mitosis in mature neurons in central nervous system by sustained depolarization. Science 192:155-157.

Cotman CW, Nadler JV (1978) Reactive synaptogenesis in the hippocampus. In: Neuronal plasticity (Cotman CW, ed), pp 227-271. New York: Raven.

Cotman C, Taylor D, Lynch G (1973) Ultrastructural changes in synapses in the dentate gyrus of the rat during development. Brain Res 63:205-213.

Crain B, Cotman C, Taplor D, Lynch G (1973) A quantitative electron microscopic study of synaptogenesis in the dentate gyrus of the rat. Brain Res 63:195-204.

Davis S, Butcher SP, Morris RG (1992) The NMDA receptor antagonist D-2-amino-5-phosphonopentanoate (D-AP5) impairs spatial learning and LTP in vivo at intracerebral concentrations comparable to those that block LTP in vitro. J Neurosci 12:21-34.

Feinendegen LE (1967) Tritium-labeled molecules in biology and medicine. New York: Academic.

Gould E, Cameron HA, McEwen BS (1994) Blockade of NMDA receptors increases cell death and birth in the developing rat dentate gyrus. J Comp Neurol 340:551-565.

Jarrard LE (1993) On the role of the hippocampus in learning and memory in the rat. Behav Neural Biol 60:9-26.

Kaplan MS, Hinds JW (1977) Neurogenesis in the adult rat: electron microscopic analysis of light radioautographs. Science 197:10921094.

Komuro H, Rakic P (1993) Modulation of neuronal migration by NMDA receptors. Science 260:95-97.

Lewis PD (1978) Kinetics of cell proliferation in the postnatal rat dentate gyrus. Neuropathol Appl Neurobiol 4:191-195.

Lipton SA (1986) Blockade of electrical activity promotes the death of mammalian retinal ganglion cells in culture. Proc Natl Acad Sci USA 83:9774-9778.

Loy R, Lynch G, Cotman CW (1977) Development of afferent lamination in the fascia dentata of the rat. Brain Res 121:229-243.

Marangos PJ, Schmechel DE (1987) Neuron specific enolase, a clinically useful marker for neurons and neuroendocrine cells. Annu Rev Neurosci 10:269-295.

Massieu L, Thedinga KH, McVey M, Fagg GE (1993) A comparative analysis of the neuroprotective properties of competitive and uncompetitive $N$-methyl-D-aspartate receptor antagonists in vivo: implications for the process of excitotoxic degeneration and its therapy. Neuroscience 55:883-892.
Matthews DA, Cotman CW, Lynch G (1976a) An electron microscopic study of lesion induced synaptogenesis in the dentate gyrus of the adult rat. I. Magnitude and time course on degeneration. Brain Res 115:1-21.

Matthews DA, Cotman CW, Lynch G (1976b) An electron microscopic study of lesion induced synaptogenesis in the dentate gyrus of the adult rat. II. Reappearance of morphologically normal synaptic contacts. Brain Res 115:23-41.

McLamb RL, Williams LR, Nanry KP, Wilson WA, Tilson HA (1990) MK-801 impedes the acquisition of a spatial memory task in rats. Pharmacol Biochem Behav 37:41-45.

Nowakowski RS, Lewin SB, Miller MW (1989) Bromodeoxyuridine immunohistochemical determination of the lengths of the cell cycle and the DNA-synthetic phase for an anatomically defined population. J Neurocytol 18:311-318.

Parpura V, Basarsky TA, Liu F (1994) Glutamate-mediated astrocyteneuron signalling. Nature 369:744-747.

Paxinos G, Watson C (1982) The rat brain in stereotaxic coordinates. Sydney: Academic.

Riva MA, Tascedda R, Molteni R, Racagni G (1994) Regulation of NMDA receptor subunit mRNA expression in the rat brain during postnatal development. Brain Res 25:209-216.

Rosenstein JM (1993) Developmental expression of neuron-specific enolase immunoreactivity and cytochrome oxidase activity in neuronal transplants. Exp Neurol 124:208-218.

Schlessinger AR, Cowan WM, Gottlieb DI (1975) An autoradiographic study of the time of origin and the pattern of granule cell migration in the dentate gyrus of the rat. J Comp Neurol 159:159-176.

Schmechel DE, Brightman MW, Marangos PJ (1980) Neurons switch from non-neuronal enolase to neuron-specific enolase during differentiation. Brain Res 190:195-214.

Schmutz J, Portet C, Jeker A, Klebs K, Vassout A, Allgeier H, Heckendorn R, Fagg GE, Olpe HR, van Riezen H (1990) The competitive NMDA receptor antagonists CGP 37849 and CGP 39551 are potent, orally-active anticonvulsants in rodents. Naunyn-Schmiedeberg's Arch Pharmacol 342:61-66.

Selleck SB, Gonzalez C, Glover DM, White K (1992) Regulation of the G1-S transition in postembryonic neuronal precursors by axon ingrowth. Nature 355:253-255.

Stanfield BB, Trice JE (1988) Evidence that granule cells generated in the dentate gyrus of adult rats extend axonal projections. Exp Brain Res 72:399-406.

Steward O (1976) Topographic organization of the projections from the entorhinal area to the hippocampal formation of the rat. J Comp Neurol 167:285-314.

Stillwell EF, Cone CF, Cone CD (1973) Stimulation of DNA synthesis in CNS neurones by sustained depolarisation. Nature New Biol 246: 110-111.

Symons JP, Davis RE, Marriott JG (1988) Water-maze learning and effects of cholinergic drugs in mouse strains with high and low hippocampal pyramidal cell counts. Life Sci $42: 375-383$

Tremblay F, Roisin MP, Represa A, Charriaut-Marlangue C, Ben-Ari Y (1988) Transient increased density of NMDA binding sites in developing rat hippocampus. Brain Res 461:393-396.

Vezzani A, Serafini R, Stasi MA, Caccia S, Conti I, Tridico RV, Samanin R (1989) Kinetics of MK-801 and its effect on quinolinic acid-induced seizures and neurotoxicity in rats. J Pharmacol Exp Ther 249:278-283.

Wimer RE, Wimer CC, Vaughn JE, Barber RP, Balvanz BA, Chernow CR (1978) The genetic organization of neuron number in the granule cell layer of the area dentata in house mice. Brain Res 157:105-122.

Wimer RE, Wimer CC, Chernow CR, Balvanz, BA (1980) The genetic organization of neuron number in the pyramidal cell layer of hippocampal region superior in house mice. Brain Res 196:59-77.

Young SH, Poo M (1983) Spontaneous release of transmitter from growth cones of embryonic neurons. Nature 305:634-637.

Zimmer J, Tonder NM, Sorensen T (1989) Hippocampus and fascia dentata transplants: anatomical organization and connections. In: The hippocampus: new vistas, Vol 52 (Chan-Palay V, Kohler C, eds), pp 257-286. New York: Liss. 